reached about 1 metre higher than today, owing to ice sheets rapidly melting between periods of growth.

To reconstruct sea level throughout the last glacial period, a team led by Jeffrey Dorale of the University of Iowa and Bogdan Onac of the University of South Florida looked to the caves that dot the southern coast of the Spanish island of Mallorca. The deposition of crusty layers of carbonate minerals in these caves records past sea levels. When the team dated these deposits, they found a period of high seas about 84,000 to 80,000 years ago that punctuated the trend in sea level decline.

If the rapid rise in sea level is confirmed by other records, it will suggest that the 100,000-year climate cycle thought to underlie recent ice ages may not fully explain the waxing and waning of ice sheets.

Alicia Newton

\section{BIODIVERSITY AND ECOLOGY}

\section{Out of step}

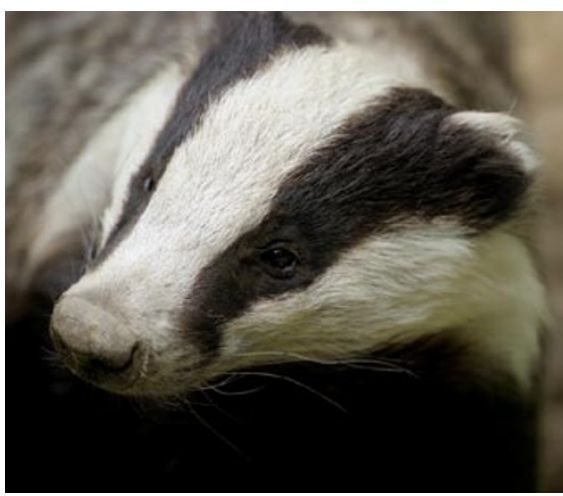

Glob. Change Biol.

doi:10.1111/j.1365-2486.2010.02165.x (2010) Recent changes in the seasonal timing of biological events such as flowering and migration have been linked to warmer temperatures. Now a study shows that such seasonal shifts are becoming increasingly common in the UK and could wreak havoc across ecosystems as they disturb the delicate balance of nature.

A team led by Stephen Thackeray of the Centre for Ecology and Hydrology in Lancaster, UK, looked at more than 25,500 records of the timing of biological events for 726 marine, terrestrial and freshwater species over a 30-year period from 1976 to 2005. During this period, all three of these environments experienced a warming trend of about $0.04-0.05^{\circ} \mathrm{C}$ per year. Thackeray and colleagues found that over the 30 years under study, the timing of 84 per cent of spring and summer events moved forward. The shift was more rapid than suggested by previous studies, averaging almost 0.4 days per year.

Many organisms time their reproduction and migrations to coincide with maximum food availability. If warming is the cause of these seasonal shifts, the new study suggests that 'trophic mismatching', in which the arrival and reproduction of predators no longer synchronizes with access to food, could be more common in future.

Olive Heffernan

\section{OCEAN SCIENCE}

\section{Souring seas}

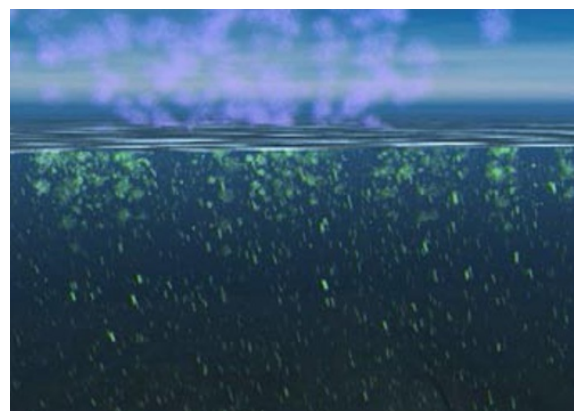

Nature Geosci. doi:10.1038/nge0755 (2010)

Marine plankton survived a period of intense ocean warming and acidification some 55 million years ago. But their future descendants might not be so lucky, suggests a new study.

Using an Earth-system model called GENIE-1, Andy Ridgwell and Daniela Schmidt of Bristol University in the UK compared possible future levels of ocean acidity to those experienced during the Palaeocene-Eocene Thermal Maximum (PETM), a period of warming during which a massive amount of carbon was released into the atmosphere. Ridgwell and Schmidt ran their model assuming a 'business as usual' greenhouse gas emissions scenario until 2100 and a linear decline in emissions thereafter. This gives a total carbon release of 2.18 trillion tonnes, similar to the amount thought to have been released during the PETM.

They found that in the future the deep ocean could become undersaturated with carbonate, the mineral form of carbon used by calcareous organisms for building shells and skeletons, to an even worse extent than during the PETM. At the ocean surface, the rate of acidification could exceed that experienced during the PETM, potentially challenging the ability of plankton to adapt.

Olive Heffernan

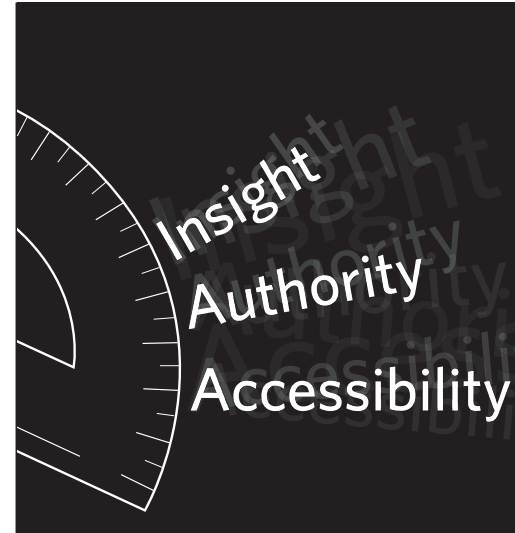

naturenews

\section{Science}

news from

a different angle

From daily science

updates to investigative journalism, from community commentary to editorial opinions, Nature brings you the most in-depth science news coverage online.

www.nature.com/news

nature publishing group npg 